Research Article

\title{
Dynamic Response and Robustness Evaluation of Cable-Supported Arch Bridges Subjected to Cable Breaking
}

\author{
Guotao Shao $\mathbb{D}^{1,2}$ Hui Jin $\mathbb{D}^{1},{ }^{2}$ Ruinian Jiang $\mathbb{D}^{3},{ }^{3}$ and Yue Xu $\mathbb{i}^{1}$ \\ ${ }^{1}$ School of Highway, Chang'an University, Xi'an, Shanxi, China \\ ${ }^{2}$ Collage of Civil Engineering and Architecture, Taizhou University, Taizhou, Zhejiang, China \\ ${ }^{3}$ Department of Engineering and Technology and Surveying Engineering, New Mexico State University, Las Cruces, NM, USA
}

Correspondence should be addressed to Hui Jin; jinhui@tzc.edu.cn

Received 29 October 2020; Revised 10 January 2021; Accepted 29 January 2021; Published 9 February 2021

Academic Editor: Salvatore Caddemi

Copyright ( $\odot 2021$ Guotao Shao et al. This is an open access article distributed under the Creative Commons Attribution License, which permits unrestricted use, distribution, and reproduction in any medium, provided the original work is properly cited.

Cable-supported arch bridges have had many cable break accidents, which led to dramatic deck damage and even progressive collapse. To investigate the dynamic response and robustness of cable-supported arch bridges subjected to cable breaking, numerical simulation methods were developed, compared, and analyzed, and an effective and accurate simulation method was presented. Then, the cable fracture of a prototype bridge was simulated, and the dynamic response of the cable system, deck, and arch rib was illustrated. Finally, the robustness evaluation indexes of the cable system, deck, and arch rib were constructed, and their robustness was evaluated. The results show that the dynamic response of the adjacent cables is proportional to the length of the broken cable, while the dynamic response of the deck is inversely proportional to the length of the broken cable. The dynamic amplification factor of the cable tension and deck displacement is within 2.0, while that of the arch rib bending moment exceeds 2.0. The break of a single cable will not trigger progressive collapse. When subjected to cable breaking, the deck system has the least robustness. The proposed cable break simulation procedure and the robustness evaluation method are applicable to both existing and new cable-supported bridges.

\section{Introduction}

Cables are the key components of cable-supported arch bridges. Due to corrosion, abrasion, and fatigue, many cable fracture accidents of cable-supported arch bridges happened in the past few years. For example, the deck of Sichuan Yibin South-Gate Bridge collapsed into river after the fracture of its eight short cables in 2001, and the Taiwan Nanfang'ao Bridge encountered a progressive collapse triggered by cable fracture in 2019. To prevent the accidental event of cable breaking, many codes have introduced an accidental load; for example, the Post Tension Institution (PTI) [1] recommends using a dynamic amplification factor (DAF) for cable-stayed bridges. However, the values of DAF vary among the codes, some of which have been found to be unreasonable in some cases.

For determining rational values of DAF, many researches have been conducted. Zoli and Woodward [2] pointed out that the result of an equivalent static analysis with a DAF of 2.0 has a larger deviation than that of a dynamic analysis. Ruiz-Teran and Aparicio [3] indicated that the DAFs of some components were larger than 2.0. In the research of cable breaking of cable-stayed bridges, both Mozos [4,5] and Zhou and Chen [6] concluded that an equivalent static analysis with a DAF of 2.0 cannot capture the extreme values of both moment and stress and should not be used in the response analysis of cable breakage events. There are also some studies that support the equivalent static method using DAF; for example, Park et al. [7] found that the DAF values were below 1.5 for the critical sections in the cable rupture of Seohae Bridge, and Cai et al. [8] pointed out that the DAF of 2.0 is a good estimate for an equivalent static analysis procedure for cable breakage of the studied cablestayed bridges. Due to the varying DAF results, further study on DAF values for cable-supported arch bridges is needed.

While dynamic analysis methods are recommended for simulation of cable breaking, some critical issues in the dynamic analysis procedure need further study, including 
the cable loss mode [9], cable loss duration [3, 10], and the effect of the material and geometry nonlinearity $[6,8,10-12]$. Some experimental studies have been conducted, such as the seven-wire steel strand specimen breakage experiment by Mozos and Aparicio [13] and the impact fracture test of a single steel wire by Hoang et al. [14]. These studies were based on specimens, which did not reflect the response of cable-supported bridge structures.

The structural performance under component loss scenarios is often evaluated by robustness and redundancy. Robustness is defined as the ability to withstand a given level of damage without suffering degradation or loss of function. Redundancy is defined as the quality of having alternative paths by which forces can be transferred [15]. The study of robustness evaluation of cable-supported bridges subjected to cable breaking has been very limited. Wolff and Starossek [16] and Cai et al. [8] concluded, respectively, that the failure of one cable would cause significant bending moments in the stiffening girder but would not lead to a zipper-type progressive collapse. Hoang et al. [14] pointed out that a progressive collapse would happen when four cables break in the studied cable-stayed bridge. The influences of cable corrosion and fatigue in the progressive collapse were also taken into consideration by Wu et al. [17] and Morgese et al. [18]. Shoghijavan et al. $[19,20]$ derived an approximation function for the stress increase ratio of the adjacent cables and found that the robustness can be improved by adjusting the rigidity of the main girder at different positions. Domaneschi et al. $[15,21]$ used the applied element method in the study of disproportionate collapse of cable-stayed bridges and found that the structural redundancy was a strategic measure for avoiding disproportionate collapse and improving robustness. No guidance has been developed for carrying out detailed robustness evaluation or optimization of cable-supported arch bridges subjected to cable breaking.

Most researchers have focused on studying the rupture of cables in cable-stayed bridges. However, different from cable-stayed bridges that have strong longitudinal stiffening girders, cable-supported arch bridges always use a grid deck with transverse girders, in which cable rupture may lead to serious damage to the bridges.

The main aim of this paper is to investigate the dynamic response and robustness of cable-supported arch bridges subjected to cable breaking. The geometry and numerical model of a prototype cable-supported arch bridge are described in Section 2. Three key issues of cable loss simulation are studied and discussed in Section 3. The dynamic responses of the cable system, deck, and arch rib are demonstrated and discussed in Section 4. The robustness evaluation indexes are calculated and applied in the bridge robustness evaluation in Section 5.

\section{System and Modeling}

Cable-supported arch bridges have excellent spanning ability, which always use half-through trusses and float deck systems. There are hundreds of cable-supported arch bridges with a span of more than $200 \mathrm{~m}$ worldwide. Two examples are the Bayonne Bridge with a span of $503.6 \mathrm{~m}$ between New
Jersey and New York and the Wushan Yangtze River Bridge with a span of $492 \mathrm{~m}$ in Chongqing, China.

The deck system of long-span arch bridges usually adopts longitudinal beams simply supported on stranger transverse beams or transverse beams fixed on stranger longitudinal beams. If a simply supported deck is used, the beam will directly collapse after the cable breaks. And if a fixed deck is used, its response under the cable fracture is similar to that of a cable-stayed bridge. Therefore, the Jiantiao Bridge was selected in this study, which is a largespan arch bridge with decks composed of box-shaped beams and flange plates.

2.1. Bridge System. The Jiantiao Bridge is a half-through concrete-filled steel tubular (CFST) arch bridge with a span of $245 \mathrm{~m}$, as shown in Figure 1. The deck width is $22.8 \mathrm{~m}$ and the distance between the transverse girders is $5.9 \mathrm{~m}$ (center to center). Double cables are used on each end of the transverse girders. The arch axis is a quadratic parabola with a rise-to-span ratio of $1 / 5$.

The arch rib is a CFST truss. The cross section of the upper and lower chords has a flat dumbbell shape, and the outer diameter of the circular tube is $800 \mathrm{~mm}$. The arch foot is protected by outer concrete, as shown in Figure 1 sections III-III. The prestressed concrete transverse girders have a box section with wide flanges that are used as part of the deck.

The cable system consists of 55 galvanized high-strength steel wires with a diameter of $7 \mathrm{~mm}$. Cables were installed on the upstream and downstream sides of the transverse girders. The downstream cables are numbered $\mathrm{S} 1$ to $\mathrm{S} 60$, and the upstream cables are numbered X1 to X60. The distance between the upstream and downstream cables is $17.4 \mathrm{~m}$, as shown in sections I-I in Figure 1. There are two cables (a pair) anchored on each side of every transverse girder, with a distance of $1.5 \mathrm{~m}$. The transverse girders are connected with a $2.9 \mathrm{~m}$ wide cast-in-place concrete slab, as shown in Figure 1 . There are 120 cables in total. The end cables (S1, S2, $\mathrm{X} 1, \mathrm{X} 2, \mathrm{~S} 59, \mathrm{~S} 60$, X59, and X60) are anchored to the upper chord of the arch rib, while the remaining cables are anchored to the lower chord of the arch rib. Cables S3, X3, S58, and X58 are the shortest cables. Due to the symmetry of the structure, the breakage of downstream S1 to S30 cables was studied in this paper.

2.2. FE Model. A three-dimension (3D) finite element (FE) model of Jiantiao Bridge was built using ANSYS, in which the arch rib, columns, and cross braces were modeled with beam elements, and the cables were modeled with truss elements. The transverse girders and the deck were modeled with shell elements.

The boundary conditions of the FE model used a fixed arch foot, and the cables were hinged to the anchorage points on the transverse girders and the arch rib. To simulate the boundary conditions of the deck, the contact pairs were used between the expansion joints. The material properties of the arch rib, transverse girders, and steel wires are listed in Table 1. 


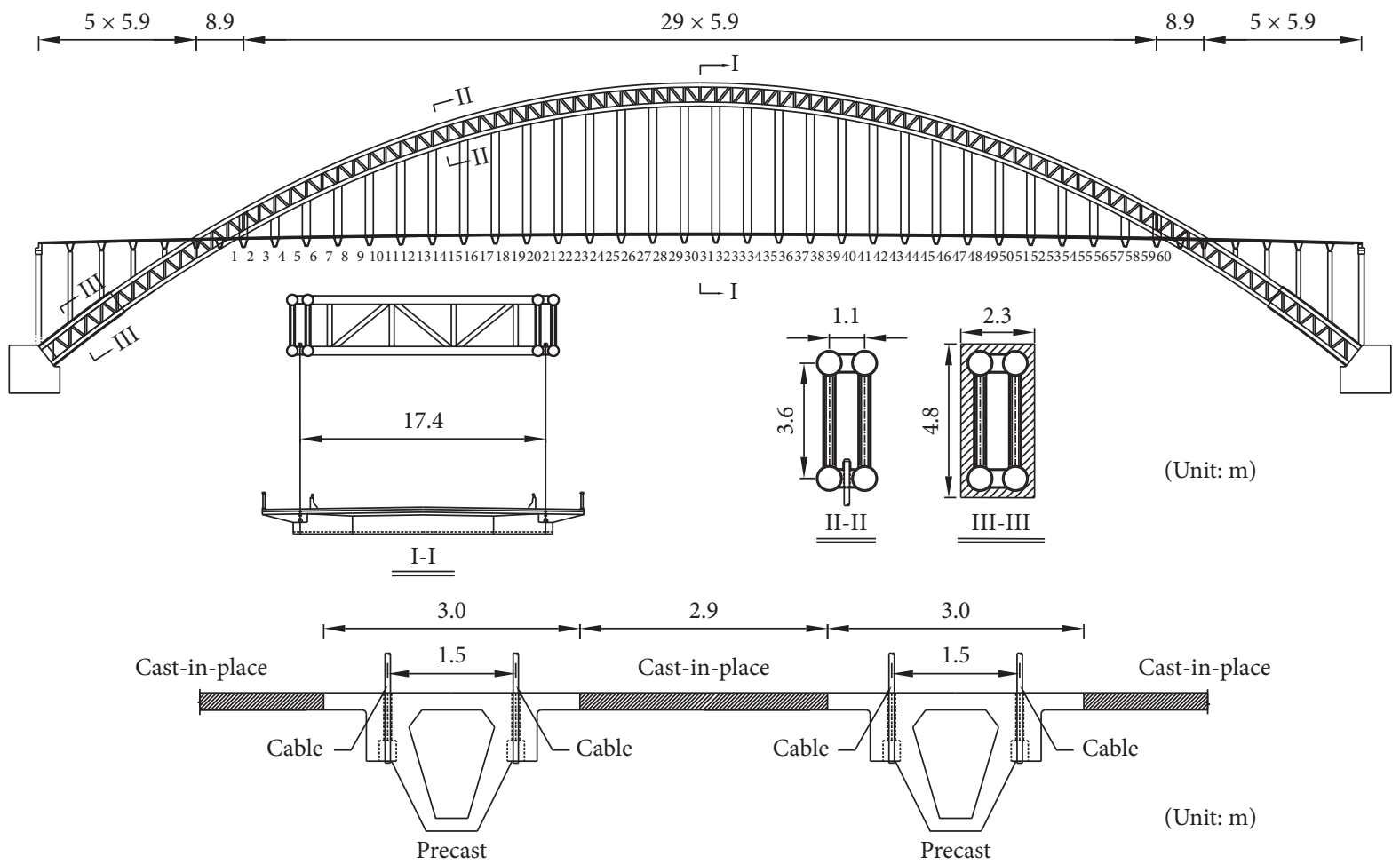

Figure 1: Configuration of the prototype cable-supported arch bridge.

TABle 1: Properties of the materials in the prototype arch bridge.

\begin{tabular}{lcccc}
\hline Properties & $\mathrm{Unit}$ & Steel & Concrete & Cable steel wire \\
\hline Weight density & $\mathrm{kN} / \mathrm{m}^{3}$ & 78 & 25 & 75 \\
Elasticity modulus & $\mathrm{GPa}$ & 210 & 34.5 & 195 \\
Poisson's ratio & $\mu$ & 0.3 & 0.2 & 0.3 \\
Compressive strength & $\mathrm{MPa}$ & 210 & 32.4 & $\mathbf{2 . 6 4}$ \\
Tensile strength & $\mathrm{MPa}$ & $\mathbf{2 1 0}$ & $\mathbf{2 . 6 4}$ & $\mathbf{1 6 7 0}$ \\
\hline
\end{tabular}

To consider the material nonlinearity, a multilinear isotropic hardening criterion in ANSYS was chosen for the concrete material, and a bilinear isotropic reinforcement criterion was chosen for the steel material. The steel wires of the cables were considered to be linearly elastic. The geometric nonlinearity of the structure was also considered by applying a large deformation effect.

The analysis process of the cable fracture started with a static analysis to obtain the initial state, and a transient analysis for cable breaking was then conducted. After cable breakage, a longer transient analysis with 50 seconds was used to trace the postbreakage dynamic response. The cable breakage simulation method is presented in Section 3. Considering the fact that most of the cable break accidents occurred because of corrosion, the dynamic analysis of cable fracture was performed under the dead load. Because cable breakage is a local effect and the previous cable breakage accidents did not cause arch bridge instability, this study does not address the stability issues.

2.3. Validation of the FE Model. To verify the accuracy of the FE model, the simulated cable tensions under the dead load were compared with those measured in the field. The on-site cable forces were measured by a cable force meter, in which an acceleration sensor was used to measure the natural frequency of cable and then converted the natural frequency to cable force. The relationship between natural frequency and cable force was expressed as

$$
T=4 \mathrm{~mL}\left(\frac{f_{n}}{n}\right)^{2}-\frac{n^{2} \pi^{2} E I}{L^{2}},
$$

where $T$ is the cable force, $m$ is the linear density, $L$ is the effective length, $f_{n}$ is the $n_{\text {th }}$ natural frequency, and $E I$ is the bending stiffness of the cable.

Figure 2 shows the comparison of the cable forces between the FE model and the field measurement. The average value of the cable forces calculated by the FE model is $367.7 \mathrm{kN}$, while that of the field measurement is $373.6 \mathrm{kN}$. The results of the FE model are close to the actual state of the bridge and the maximum difference between the two is within $5 \%$.

\section{Cable Break Simulation Method}

3.1. Cable Break Mode. There are two main methods for simulating cable breaks. One method is to remove the 


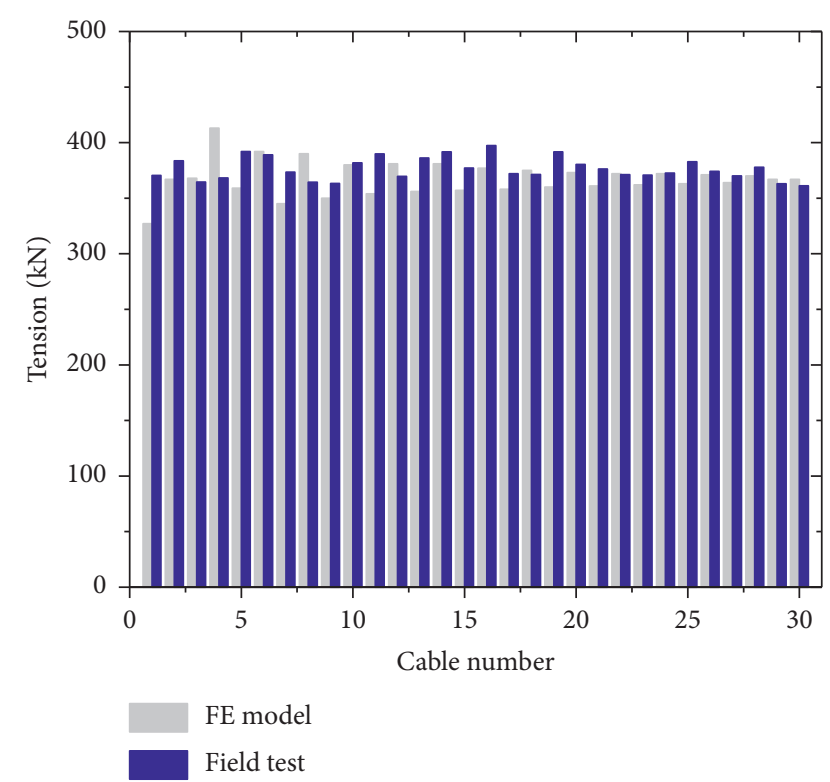

FIgURE 2: Comparison between the calculated and measured cable forces.

broken cable element and use the equivalent functions. Hoang et al. [14] and Olamigoke [22] simulated the cable breakage by using an impact waveform after removing the cable elements. Wolff and Starossek [16] and Park et al. [7] simulated the cable breakage by using a transient load to the anchorage nodes. Zoli and Woodward [2] simulated a cable loss event by using an abrupt drop in a forcing function. Zhou and Chen [6] demonstrated that it is more accurate to remove the broken cable element in the static analysis stage before the dynamic analysis. The other method is to directly remove the cable element or reduce the cable element area. Mozos [4, 13] and Wu et al. [17] simulated a cable loss by directly reducing the area of the damaged cable in the first step of a dynamic analysis. The main difference between the two methods lies in whether or not using a force function to represent the cable force. Zhou and Chen [10] used a reduced cable area and a force function to simulate the cable fracture process but ignored the fact that the loss of cable area is not proportional to the loss of force, which was demonstrated by $\mathrm{Xu}$ et al. [23].

When a force function is used, the form of the function determines the accuracy of the calculation. Ruiz-Teran and Aparicio [3] compared seven types of force functions and pointed out that when the breakage time is sufficiently short, the maximum response is irrespective of the way in which the cable breaks. To avoid an inappropriate function, directly removing the damaged cables in a suitable cable loss duration is less error-prone and consistent with the actual situation.

It should be noted that removing an element directly is appropriate for simulating fractures caused by rust and fatigue; however, it is not applicable to the situation where the cable fractured by hitting. Because most of the long-span arch bridge cable fractures are caused by corrosion and fatigue, the mode of directly removing the failed cable is chosen in this paper to simulate the cable loss.
3.2. Cable Break Duration. There is currently limited research on the duration of cable breakage. Fracture experiments were conducted by Mozos and Aparicio [13] on a seven-wire strand of a specific steel type; the result shows that the average rupture time is $0.0055 \mathrm{~s}$. The impact fracture test by Hoang et al. [14] on a single wire indicated that the duration of the cable breaking process is $0.017 \mathrm{~s}$. Because the cable types differ for different bridges, the fracture duration varies.

A parametric analysis was carried out for determining a reasonable cable break duration for the arch bridge in this study. Six break durations of $0.01 \mathrm{~s}, 0.1 \mathrm{~s}, 1.0 \mathrm{~s}, 2.0 \mathrm{~s}, 4.0 \mathrm{~s}$, and $10.0 \mathrm{~s}$ were selected, and the tension of S30 caused by the cable break of S29 was used for comparison.

Figure 3 depicts the dynamic response for each cable break duration. As observed, the maximum dynamic response was reached in the durations of $0.01 \mathrm{~s}, 0.1 \mathrm{~s}$, and $1.0 \mathrm{~s}$. When the fracture duration increases from $2.0 \mathrm{~s}$ to $10.0 \mathrm{~s}$, the peak response gradually decreases. The dynamic curves of $2.0 \mathrm{~s}, 4.0 \mathrm{~s}$, and $10.0 \mathrm{~s}$ show that the cable force increases linearly in the initial stage, which reflected the shortage of the direct-removing-cable method. It also shows that if the fracture duration is less than $1.0 \mathrm{~s}$, the dynamic response curves almost coincide, and the maximum response is consistent, which was also demonstrated by Ruiz-Teran and Aparicio [3]. Therefore, the abrupt breakage duration was assumed to be $0.1 \mathrm{~s}$ in this study.

3.3. Damping Coefficient. In long-span cable-supported bridges, the effect of damping on the dynamic response is significant. The Rayleigh damping function is defined via the following equations as

$$
\begin{gathered}
{[C]=\alpha[M]+\beta[K],} \\
\alpha=\zeta \frac{2 \omega_{i} \omega_{j}}{\omega_{i}+\omega_{j}}, \\
\beta=\zeta \frac{2}{\omega_{i}+\omega_{j}},
\end{gathered}
$$

where the damping matrix $C$ is proportional to the mass matrix $M$ and the stiffness matrix $K . \alpha$ is the mass factor and $\beta$ is the stiffness factor; $\alpha$ and $\beta$ can be computed based on the undamped modal frequencies $\omega_{i}$ and $\omega_{j}$ and the prescribed damping ratio $\zeta$. For cable-supported bridges, the structural vibration excited by cable rupture is a local vibration around the broken cable. Wolff and Starossek [16] pointed out that the high-order modes characterized by a local vibration should be considered in Rayleigh damping. Zoli and Woodward [2] recommend taking at least 20th frequency (preferably 50th frequency) to calculate $\alpha$ and $\beta$. Through the modal analysis of the Jiantiao Bridge, it was found that the local vibration corresponds to modes greater than the 30th order. To obtain the appropriate damping coefficient, the damping ratios of the 1st, 2nd, 20th, 50th, and 100th natural frequencies were selected and the value of $\zeta$ was set as $5 \%$. 


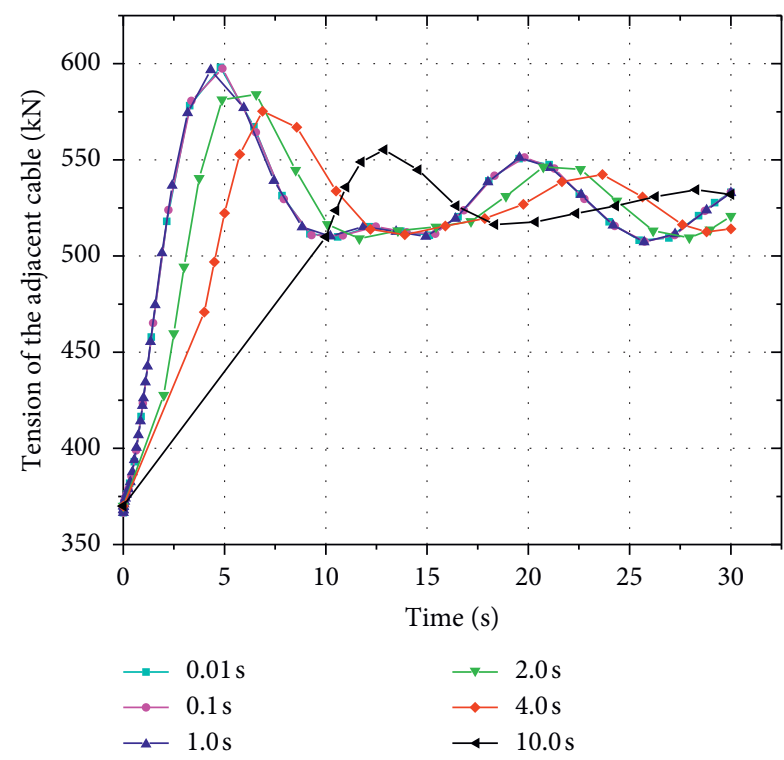

Figure 3: Dynamic response to six cable break durations.

Figure 4 displays the damping ratio curves obtained under each frequency combination. The damping ratio $\zeta_{1,2}$, which was calculated using $\omega_{1}$ and $\omega_{2}$, showed significant suppression of high-order vibrations. The value of $\zeta_{1,2}$ in the 50 th order mode is $22 \%$, and the value of the 100 th order is $33 \%$, which greatly exceeded the design value of $5 \%$. The damping ratios $\zeta_{1,20}$ and $\zeta_{1,50}$ show a better fit within the first 50th order. The damping ratio $\zeta_{1,100}$ keeps at $3 \%-5 \%$ on a high-order frequency, which matches the damping characteristics of reinforced concrete structures; therefore, $\zeta_{1,100}$ was chosen as the damping ratio in this study.

\section{Dynamic Response Results}

4.1. Tension in Adjacent Cables. Figure 5 presents the adjacent cable tension time-history curves subjected to the breakage of short cables S1(5a) and S2 (5b), respectively. It can be observed in Figures 5(a) and 5(b) that the breakage of cable S1 has the largest impact on cable S2, while the breakage of cable S2 has the largest impact on cable S1. This indicates that after a single cable breaks, the closest cable receives the maximum dynamic impact. The maximum dynamic response is 2.2 times as big as the cable tension under the dead load. The breaking of the downstream cables has little effect on the cables on the upstream side (X1 and X2 in the figure), and the maximum dynamic response of the cables on the same side is within 1.2 times of the tension under the dead load.

Figure 6 illustrates the adjacent cable tension timehistory curves subjected to the break of long cables S29 (6a) and S30 (6b), respectively. It can be observed that the breakage of cable S29 has the largest impact on cable S30, and that of cable S30 has the largest impact on cable S29, which is similar to the short-cable cases. However, the maximum dynamic response of the cable tension was 1.7 times the tension of the dead load for the long-cable breakage, and the peak value of the dynamic response is significantly smaller than that of the short cables. The breakage of long cables results in a greater dynamic response of the farther cables; for example, the maximum response of S28, which was anchored on the adjacent transverse grid, is 1.4 times of the dead-load tension when cable S29 breaks. The effect on the cables on the upstream side is slight, which is the same as that in the short-cable cases.

Figure 7 depicts the maximum tension in the adjacent cables caused by a single cable break. It can be observed that the maximum cable force of $821 \mathrm{kN}$ was caused by the break of S3, which is the shortest cable. As the length of the cable increases, the impact effect due to the break of the cable gradually decreases. For the tension of all cables caused by a single cable break, the maximum value is 1.6 to 2.2 times as big as the tension under the dead load.

4.2. Displacement of the Deck. The displacement of the lower cable anchorage points was selected to investigate the vibration of the deck. The displacement time-history curves of the deck due to the break of a short cable (S1 and S2) and a long cable (S29 and S30) are presented in Figures 8 and 9, respectively.

Figure 8 shows the displacement time-history curves due to the break of cables S1 (8a) and S2 (8b), respectively. As shown in Figure 8 , the breakage of a cable causes the maximum dynamic displacement at its own anchor point. The maximum displacement of $\mathrm{S} 1$ is $-11.3 \mathrm{~mm}$ and that of $\mathrm{S} 2$ is $-11.9 \mathrm{~mm}$. The displacement at the anchorage point of the adjacent cables located at the same transverse girder is slightly smaller than that of the broken cable. The displacements of the anchorage points that are not on the same transverse girder of the broken cable are significantly smaller.

Figure 9 shows the displacement time-history curves due to the break of long cables S29 (9a) and S30 (9b), respectively. Compared with the short-cable break, the long-cable break also caused the largest displacement at its own anchorage point, but the deck displacement was larger. The maximum displacement of $\mathrm{S} 29$ is $-27.7 \mathrm{~mm}$ and S30 is $-27.9 \mathrm{~mm}$. Moreover, the maximum displacement of the anchorage points of the adjacent cables anchored on different transverse girders also exceeds $-10 \mathrm{~mm}$.

The maximum deck displacement caused by the breakage of each cable is shown in Figure 10. It is noticed that the minimum deck displacement is $8.4 \mathrm{~mm}$, which is caused by the break of the shortest cable (S3), and the maximum deck displacement is $27.9 \mathrm{~mm}$, which is caused by the break of the longest cable (S30). The displacement of the bridge deck almost increases proportionally with the length of the cable.

4.3. Moments of the Arch Rib. To determine the impact effect of cable fracture on the arch rib, the bending moment timehistory curves at the six nodes around the upper anchorage point of the broken cable were selected. The six rigid frame node bending moments are the upper chord node bending moment $M_{T}$, lower chord node bending moment $M_{B}$, upper left node bending moment $M_{L T}$, lower left node bending 


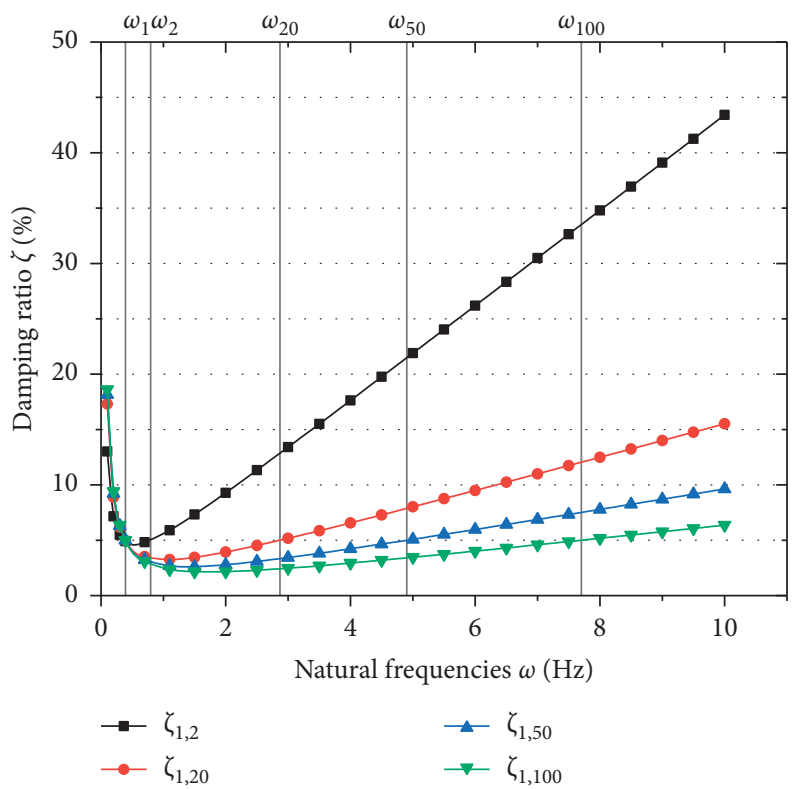

FIGURE 4: Damping ratio curves obtained under four frequency combinations.

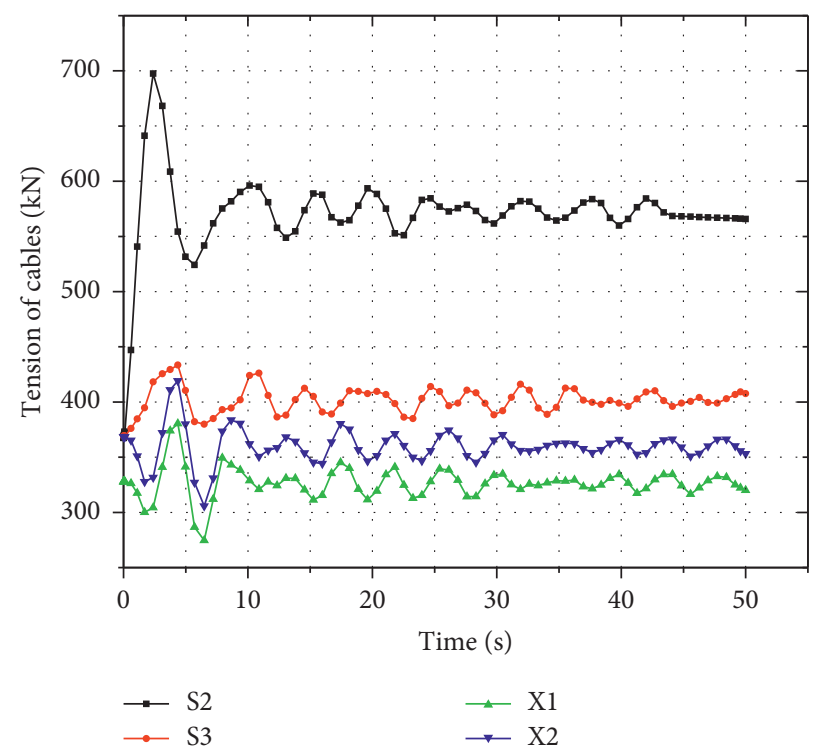

(a)

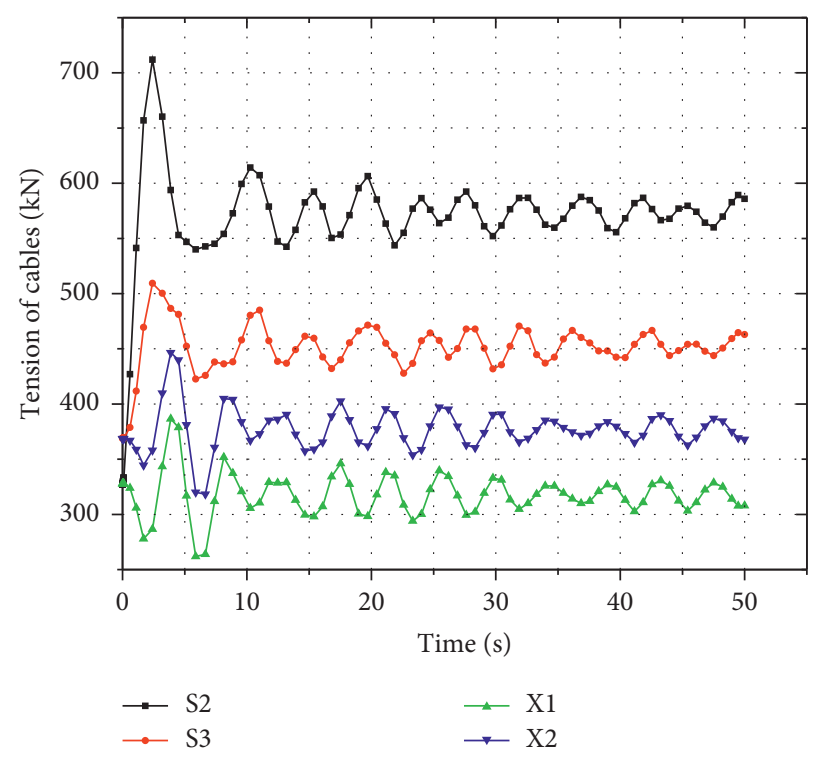

(b)

Figure 5: Tension time-history curves due to short-cable fracture: (a) break of cable S1; (b) break of cable S2.

moment $M_{L B}$, upper right node bending moment $M_{R T}$, and lower right node bending moment $M_{R B}$.

Figure 11 depicts the moment time-history curves due to the breakage of short cables S1 (11a) and S2 (11b), respectively. Because cables S1 and S2 are anchored on the upper chord of the arch rib, the dynamic response variation of $M_{T}$ is the most significant. The maximum changes of $M_{T}$ are $135 \mathrm{kN} \cdot \mathrm{m}$ due to the break of $\mathrm{S} 1$ and $150 \mathrm{kN} \cdot \mathrm{m}$ due to the break of S2. The bending moment changes at other positions are small; all are within $100 \mathrm{kN} \cdot \mathrm{m}$.

Figure 12 indicates the bending moment time-history curves due to the breakage of long cables S29 (12a) and S30 (12b), respectively. Because cables S29 and S30 are anchored on the lower chord of the arch rib, the variation of the dynamic response of $M_{B}$ is the most significant. The maximum changes of $M_{B}$ are $168 \mathrm{kN} \cdot \mathrm{m}$ due to the break of S29 and $170 \mathrm{kN} \cdot \mathrm{m}$ due to the break of $\mathrm{S} 30$. The maximum change of $M_{L B}$ and $M_{R B}$ is $145 \mathrm{kN} \cdot \mathrm{m}$, and the changes of $M_{L T}, M_{T}$, and $M_{R T}$ are within $100 \mathrm{kN} \cdot \mathrm{m}$.

The bending moment in the upper and lower chords of the arch rib is investigated. Figure 13 displays the envelope of the bending moments of the arch rib sections caused by the breakage of each cable. The bending moment of the upper chord sections is between $-100 \mathrm{kN} \cdot \mathrm{m}$ and $210 \mathrm{kN} \cdot \mathrm{m}$, and 


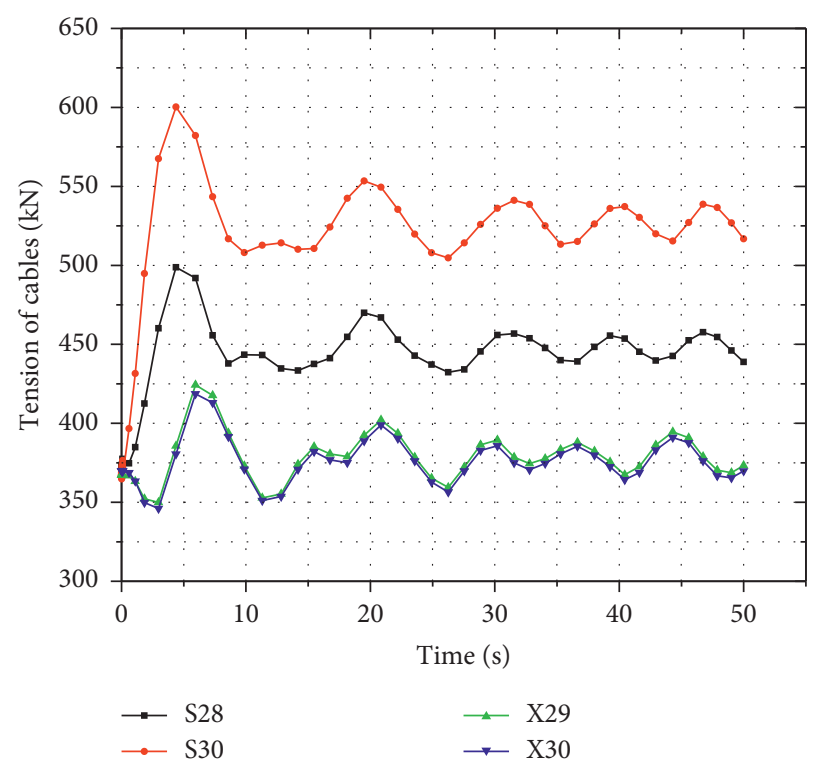

(a)

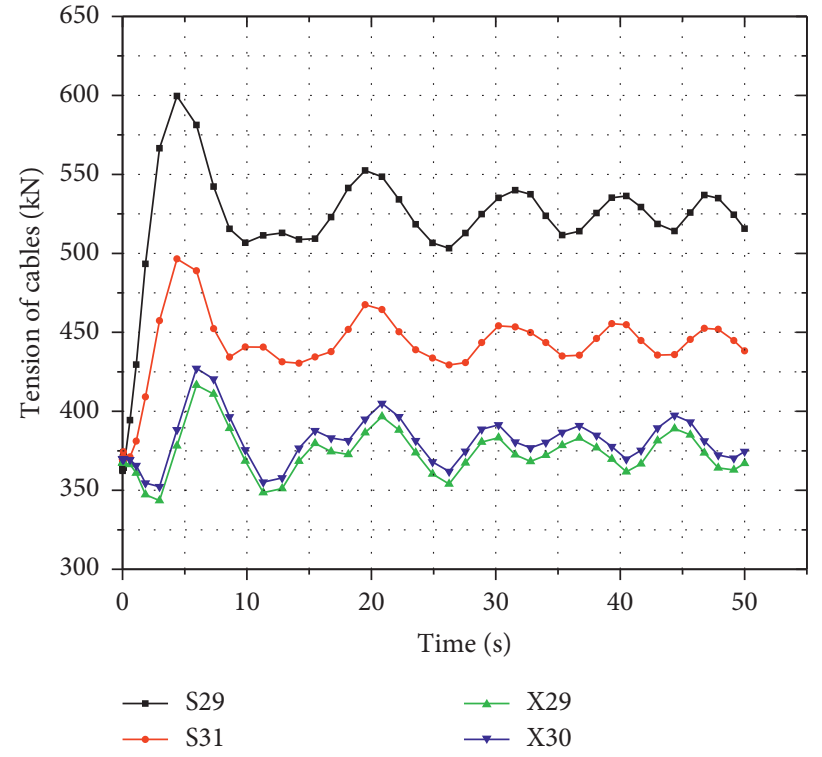

(b)

Figure 6: Time-history curves due to long-cable fracture: (a) break of cable S29; (b) break of cable S30.

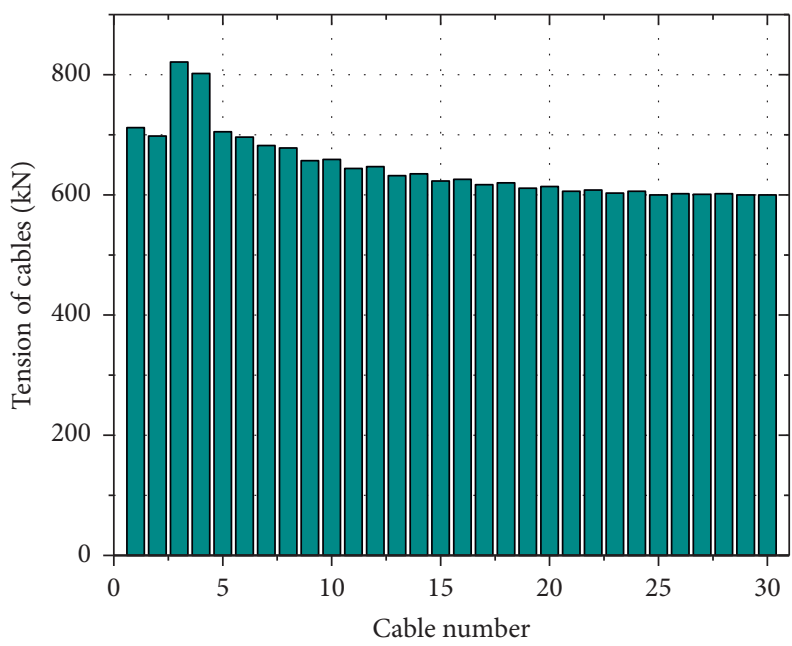

FIGURE 7: Maximum tension of the adjacent cables caused by the break of a single cable.

that of the lower chord is between $-100 \mathrm{kN} \cdot \mathrm{m}$ and $450 \mathrm{kN} \cdot \mathrm{m}$. This indicates that the bending moment of the lower chord of the arch rib is greater than that of the upper chord.

In order to reflect the variation amplitude of the arch rib bending moment during the breakage of each cable, Figure 14 shows the bending moment variation of the upper and lower chords of the arch rib caused by a single cable break. The variation of the bending moment of the upper chord is between $113 \mathrm{kN} \cdot \mathrm{m}$ and $188 \mathrm{kN} \cdot \mathrm{m}$ with an average value of $137 \mathrm{kN} \cdot \mathrm{m}$, and the bending moment variation of the lower arch rib is between $100 \mathrm{kN}$ and $280 \mathrm{kN} \cdot \mathrm{m}$, with an average value of $229 \mathrm{kN} \cdot \mathrm{m}$. Because most cables are anchored to the lower chord except S1 and S2, the bending moments of the lower chord vary more than that of the upper chord. Moreover, as the length of the cable increases, the fracture impact effect increases.
4.4. DAF of the Cable, Deck, and Rib. No specifications have provided details for calculating the DAF of cable-supported arch bridges. For the design of cable-stayed bridges, the DAF is set between 1.5 and 2.0 in some codes and recommendations. In this section, the cable failure of the Jiantiao Bridge is investigated to discuss the DAF for the cable tension, deck displacement, and arch rib bending moment of cable-supported arch bridges. Equation (1) is used to calculate DAF:

$$
\mathrm{DAF}=\frac{R_{D}-R_{0}}{R_{P D}-R_{0}}
$$

where $R_{D}$ represents the maximum dynamic response, $R_{0}$ the initial state under the dead load before cable break, and $R_{P D}$ the stable value after cable break. 


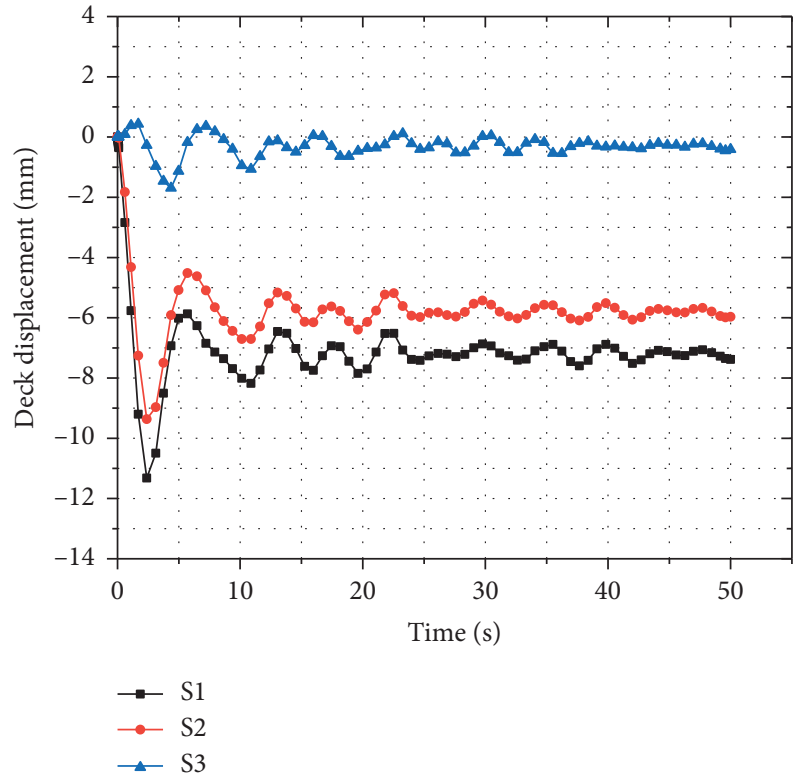

(a)

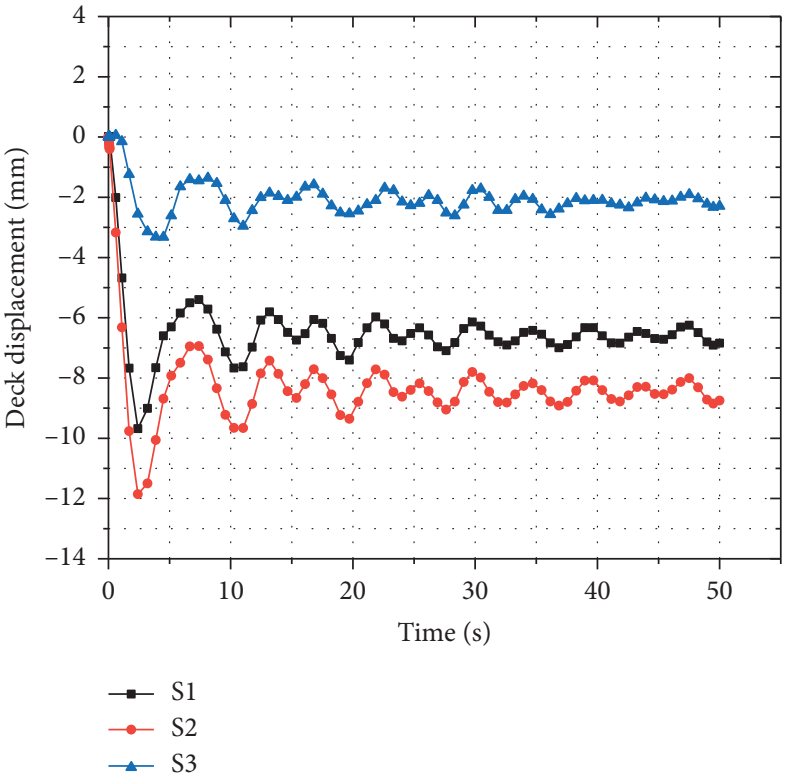

(b)

FIGURE 8: Displacement time-history curves of the deck: (a) cable S1 break; (b) cable S2 break.

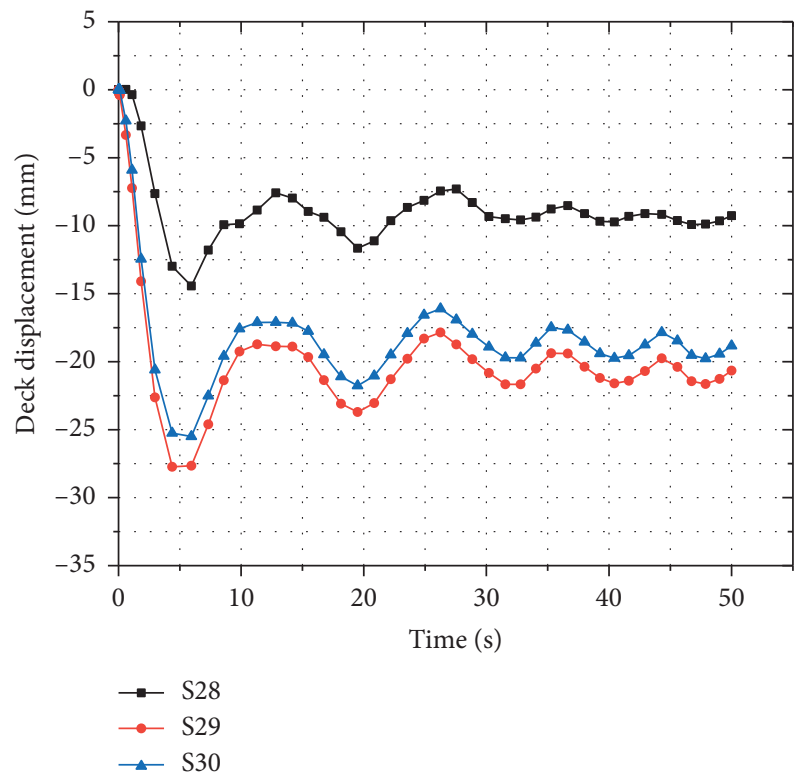

(a)

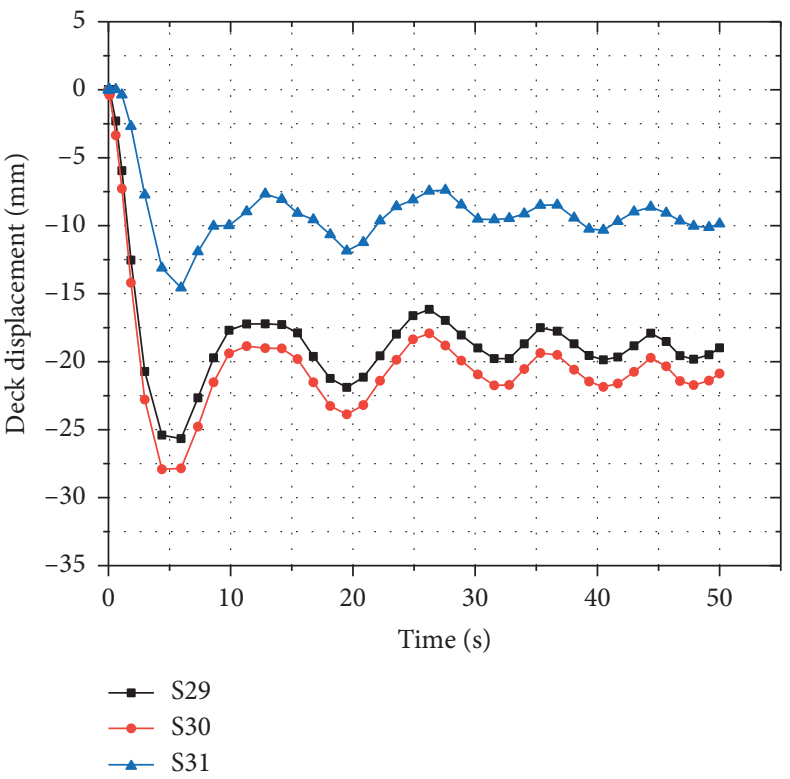

(b)

FIgURE 9: Displacement time-history curves of the deck: (a) cable S29 break; (b) cable S30 break.

Figure 15 shows the calculated DAF for the cable tension due to the break of the adjacent cable. It can be observed that the DAF of the adjacent cable tension is distributed between 1.4 and 1.6, with an average value of 1.54 .

Figure 16 presents the DAF for the deck displacement, which is between 1.30 and 1.65 with an average value of 1.40. There is a tendency for the deck displacement DAF to decrease as the cable length increases.

Figure 17 displays the DAF for the arch rib bending moment, which is between 1.5 and 2.4, with an average value of 1.93. The DAF exceeds 2.0 in some cases, which is the recommended value of PTI [1].

Compared with the recommended common DAF value of 2.0 for cable-stayed bridges by PTI [1], the DAF of the cable-supported arch bridge in this study varies for each component. The maximum DAFs of the cable tension and deck displacement are less than 2.0, while the maximum DAF of the bending moment of the arch rib exceeds 2.0. This shows that adopting a common DAF for all the components of cable-supported arch bridge structures is not advisable. 


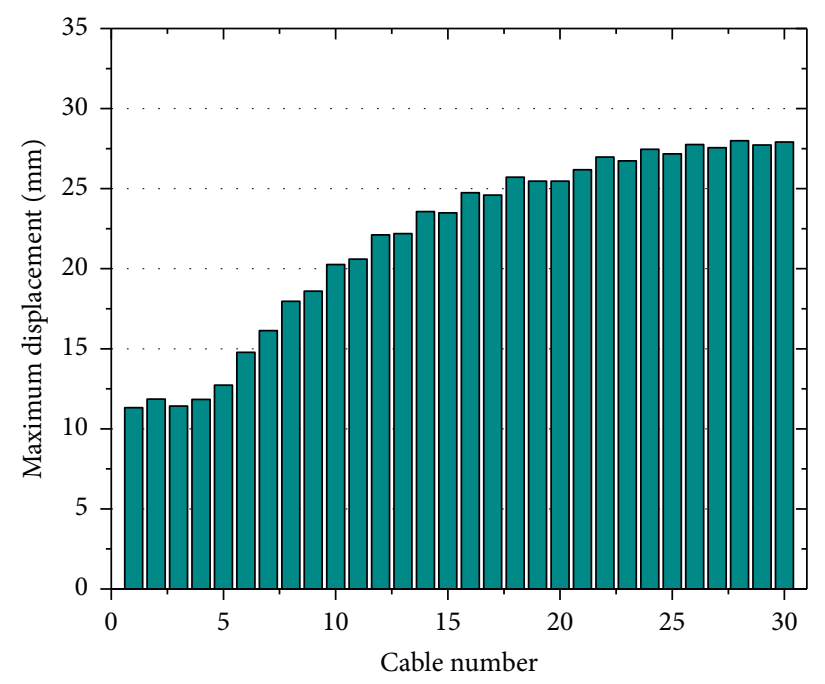

FIGURE 10: Maximum displacement of the deck caused by a single cable break.

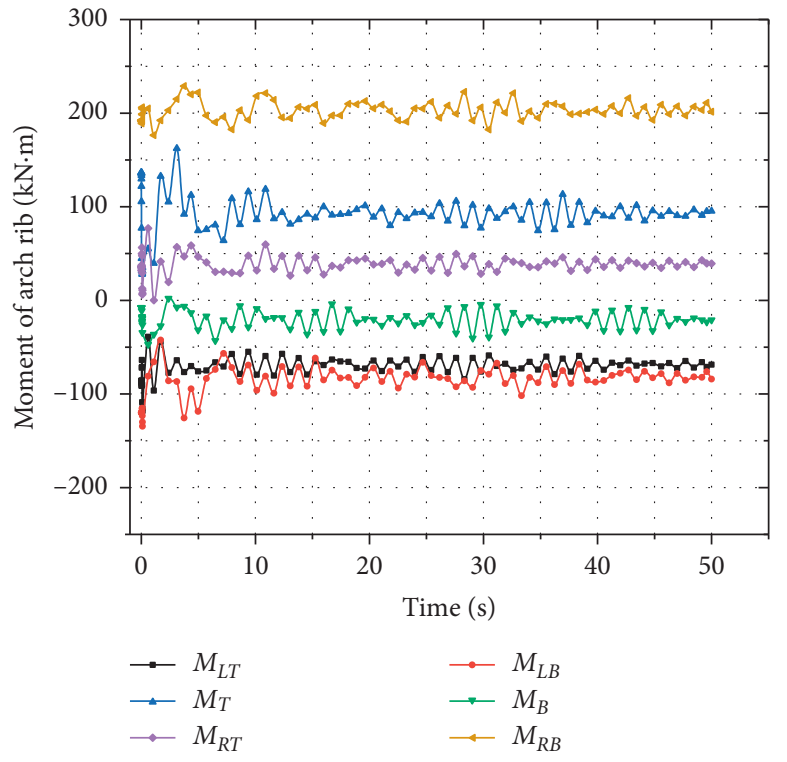

(a)

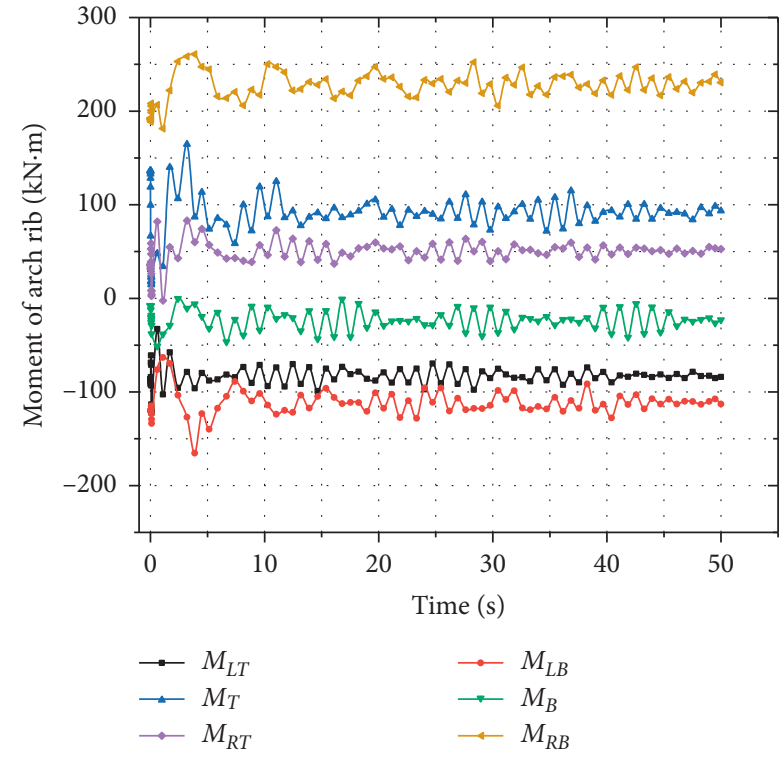

(b)

Figure 11: Bending moment time-history curves of the arch rib: (a) cable S1 break; (b) cable S2 break.

\section{Robustness Evaluation}

For long-span cable-supported arch bridges, the failure of a single cable may trigger progressive fracture of adjacent cables and damage to the deck and arch ribs. Therefore, it is necessary to evaluate the robustness of cable-supported arch bridges subjected to cable breaking. This section discusses the robustness evaluation of the cable system, deck, and arch rib subjected to a single cable break.

5.1. Robustness of the Cable System. To study the possibility of a progressive fracture of adjacent cables subjected to a single cable break, the impact effect of the cable breakage is investigated and compared with the carrying capacity of the cable system. The cable system of the Jiantiao Bridge is composed of 55 parallel steel wires that have a diameter of $7 \mathrm{~mm}$ and a tensile strength of $1670 \mathrm{MPa}$. The cable's ultimate bearing capability $f_{u}$ is $3530 \mathrm{kN}$, which is much bigger than the maximum dynamic load of $821 \mathrm{kN}$ caused by a single cable break. This indicates that a single cable breakage under the dead load will not trigger a progressive fracture of the adjacent cables.

Furthermore, to consider the load combination with reference to the PTI [1] recommendation and the study by Zoli and Woodward [2], the limit state design combination $T_{d}$ and the accidental combination $T_{f}$ of the cable failure are defined as 


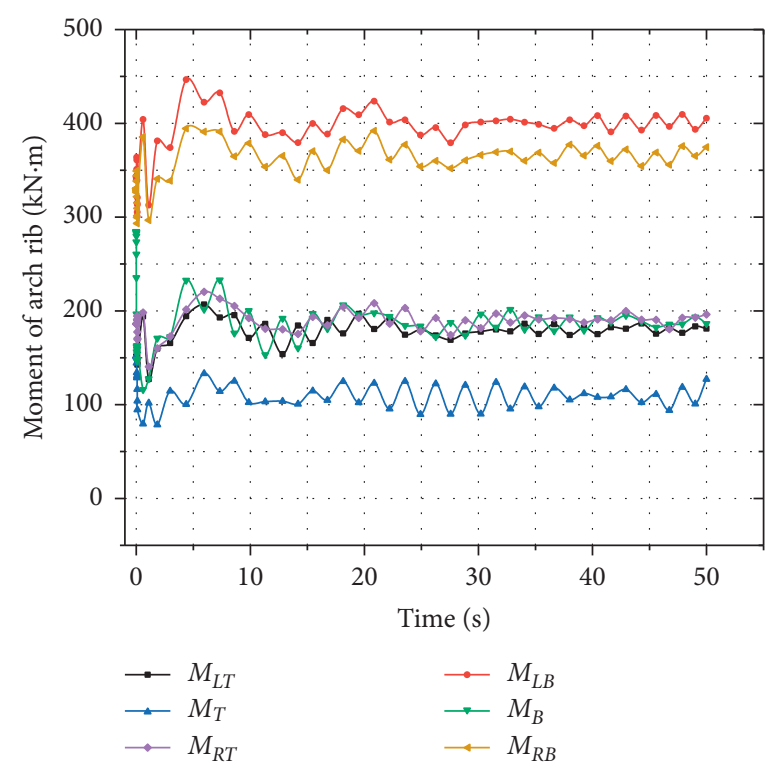

(a)

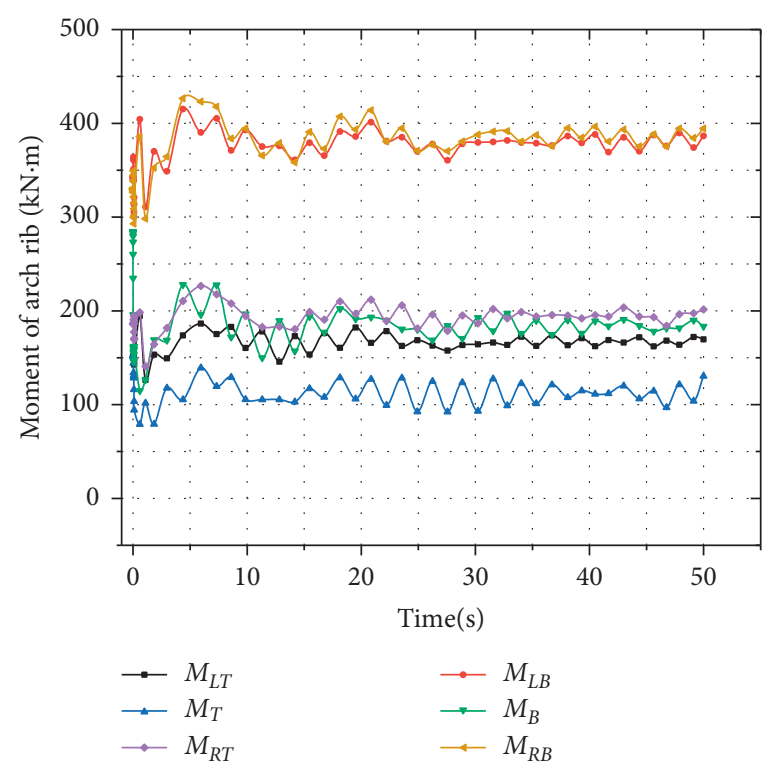

(b)

FIgURE 12: Bending moment time-history curves of the arch rib: (a) cable S29 break; (b) cable S30 break.

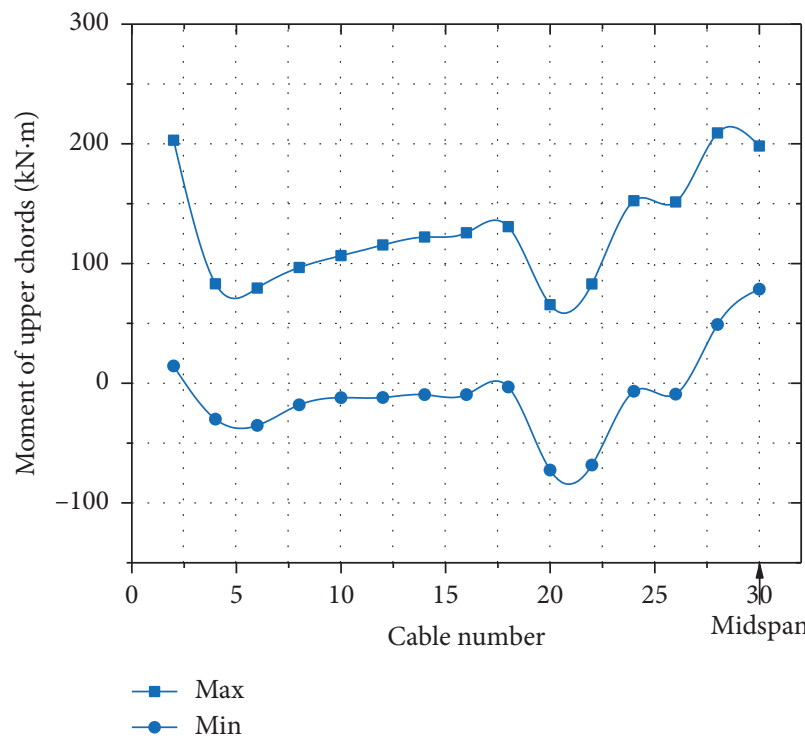

(a)

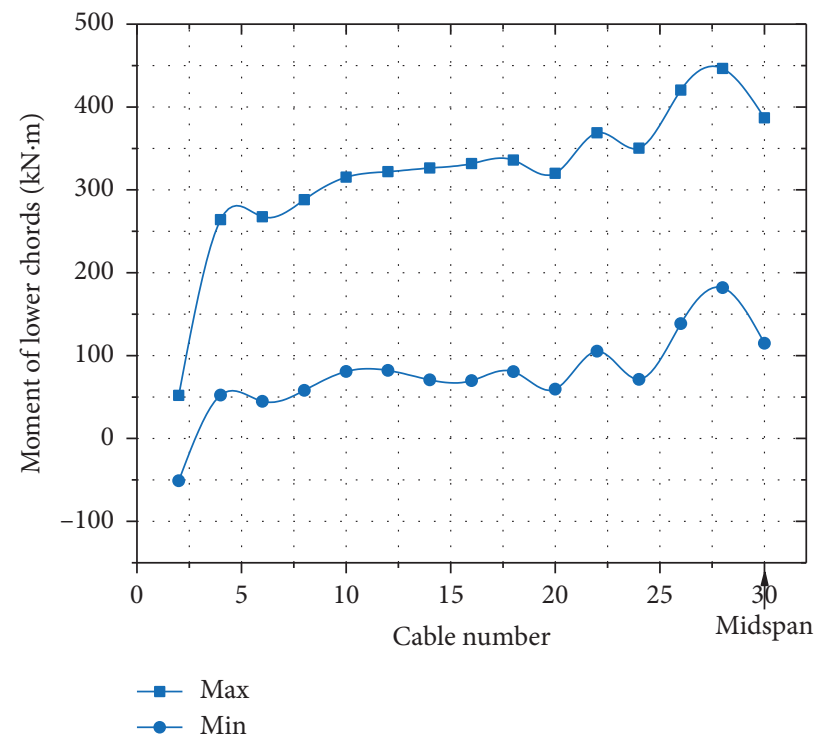

(b)

FIGURE 13: Envelope of the arch rib bending moment subjected to a single cable break: (a) upper chords; (b) lower chords.

$$
\begin{aligned}
& T_{d}=1.2 T_{s}+1.4 T_{v}+0.75\left(T_{p}+T_{t}\right), \\
& T_{f}=1.2 T_{s}+0.75\left(T_{v}+T_{p}+T_{t}\right)+T_{c},
\end{aligned}
$$

where $T_{s}, T_{v}, T_{p}$, and $T_{t}$ are the tension of the dead load, vehicle load, pedestrian load, and temperature load, respectively. $T_{c}$ is the net dynamic effect of the cable break, which is equal to the maximum tension of the dynamic response minus the cable tension under the dead load.

Figure 18 shows the comparison of the design limit combination $T_{d}$ and the accidental combination $T_{f}$ of each cable. It is observed that the values of cable fracture accidental combination are all higher than the carrying capability limit state combination. This means that the cable breakage accidental combination is the most unfavorable situation and should not be ignored in the design stage.

The maximum value of the accidental combination $T_{f}$ is $1130 \mathrm{kN}$, and the minimum safety factor of the cable compared with the ultimate bearing capability $f_{u}$ is 3.1 . It shows that the cable system has good robustness under a cable breakage accidental combination, and a single cable 


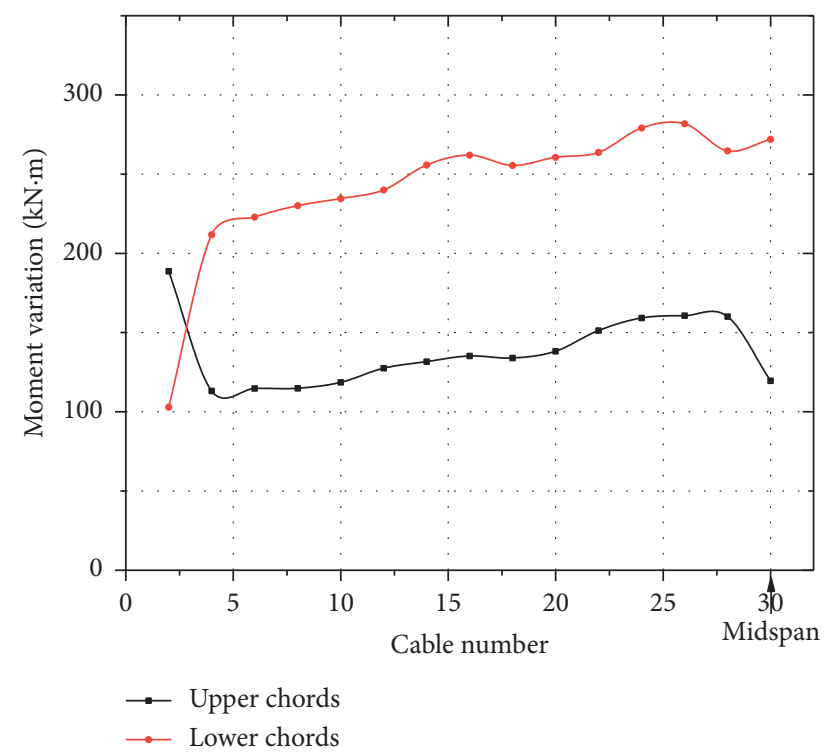

Figure 14: Moment variation of arch rib chords caused by a single cable break.

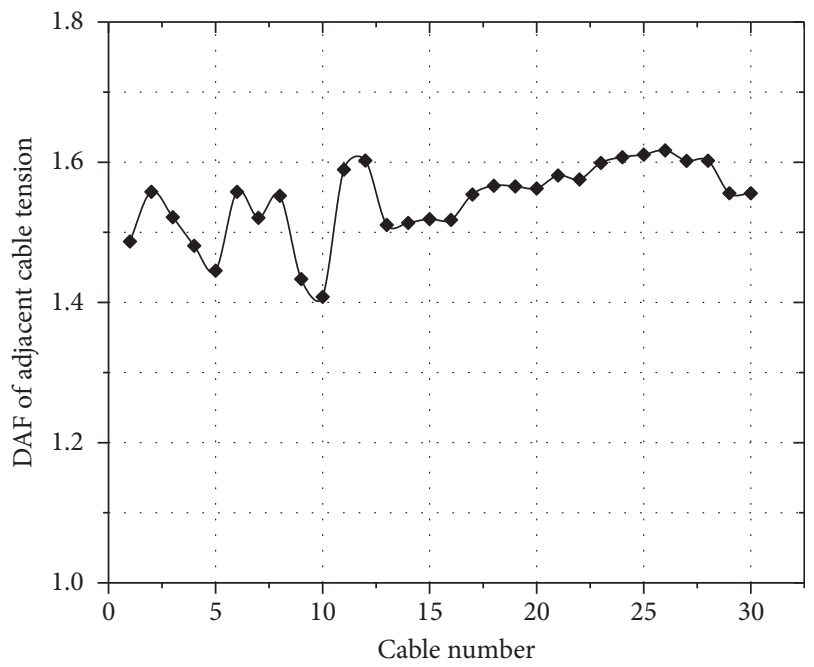

FIGURE 15: DAF of the cable tension caused by a single cable break.

break will not trigger a progressive breakage of adjacent cables.

5.2. Robustness of the Deck. Different from cable-stayed bridges that have a strong longitudinal stiffening girder, cable-supported arch bridge deck systems always use transverse girders as the main load-bearing members. To evaluate the damage to the deck system, the capability of the deck was obtained by a pushover analysis.

The pushover model was composed of three transverse girders with its flange plate. An elastic support was used to simulate the rigidity of the cables at the anchoring positions. The horizontal side displacement of the deck was not allowed by fixing the left and right ends of the deck system to avoid any rigid movement. The vertical pushover load was applied to the anchored position of the broken cable, on the

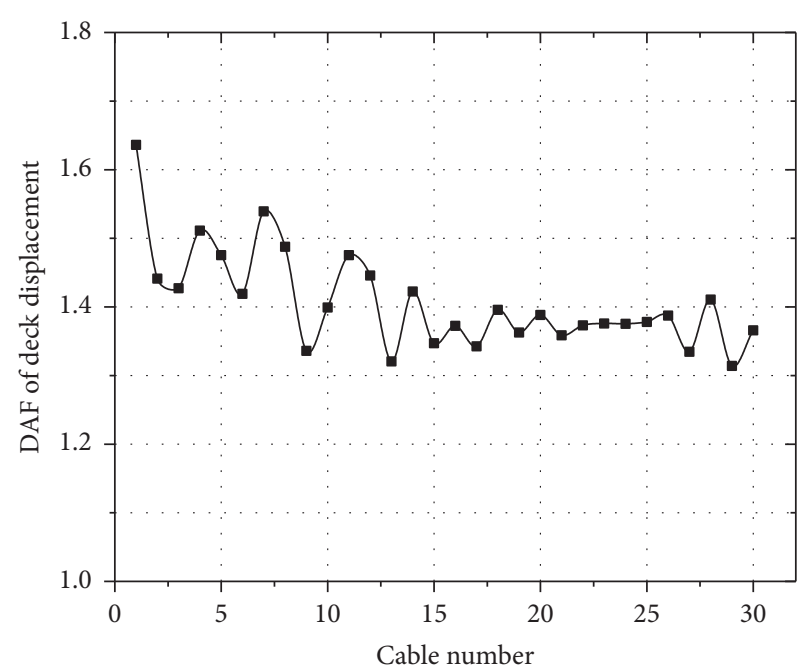

FIGURE 16: DAF of the deck displacement caused by a single cable break.

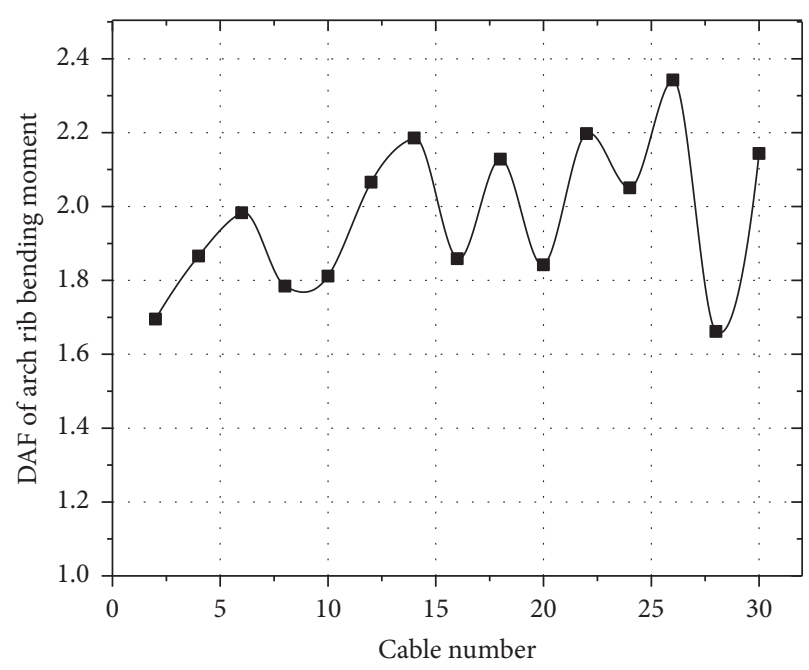

FIGURE 17: DAF of the arch rib moment caused by a single cable break.

right side of the middle girder, as indicated by the arrow in Figure 19. The relative displacements between the transverse girders were chosen as the capability index to represent the bearing capacity of the deck system.

Figure 20 depicts the load-displacement curve of the deck. It can be noticed that the failure process of the deck can be divided into three stages: elastic stage, cracked stage, and failure stage. When the relative displacement is less than $2.35 \mathrm{~mm}$, the deck is in the elastic stage. When the relative displacement increases from $2.35 \mathrm{~mm}$ to $31.5 \mathrm{~mm}$, cracks gradually increase and the deck works with the cracks. When the relative displacement exceeds $31.5 \mathrm{~mm}$, the longitudinal reinforcement yields and the displacement increases rapidly.

The robustness of the deck was evaluated by comparing the relative displacement of the cable breakage with that of the load-displacement curve. As displayed in Figure 21, the maximum relative displacement of the deck is between $8 \mathrm{~mm}$ and $15 \mathrm{~mm}$ subjected to a single cable break, which increases 


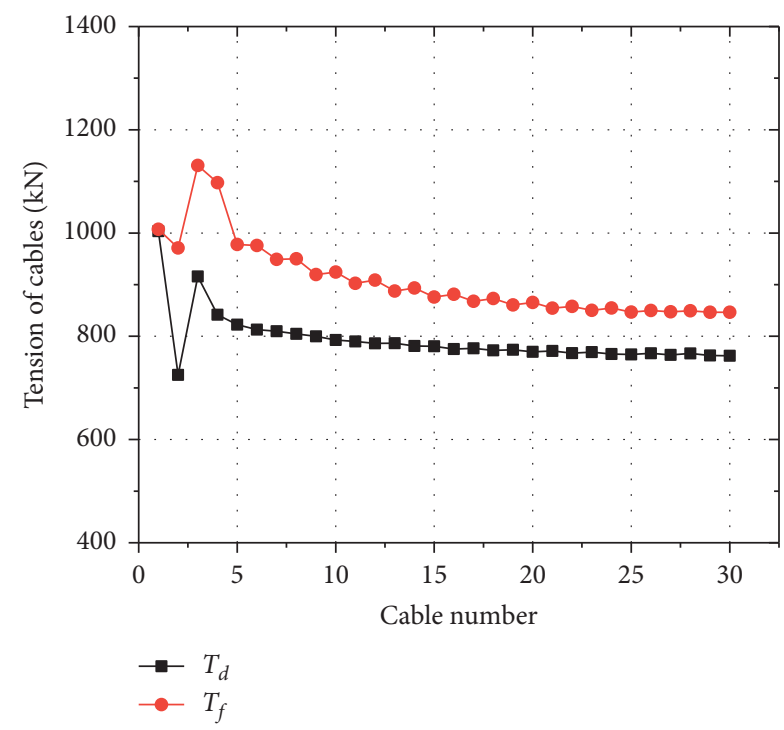

FIgURE 18: Comparison of the limit state combination $T_{d}$ and accidental combination $T_{f}$ of each cable.

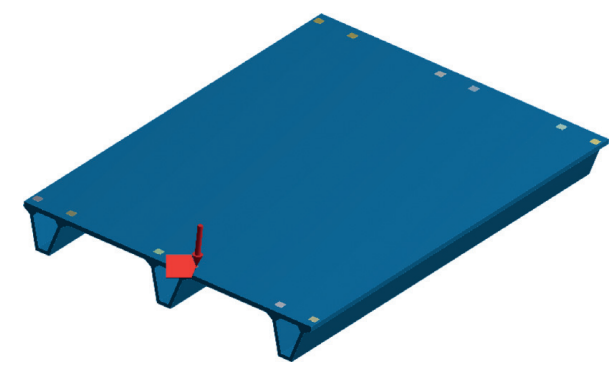

Figure 19: Pushover model of the deck system.

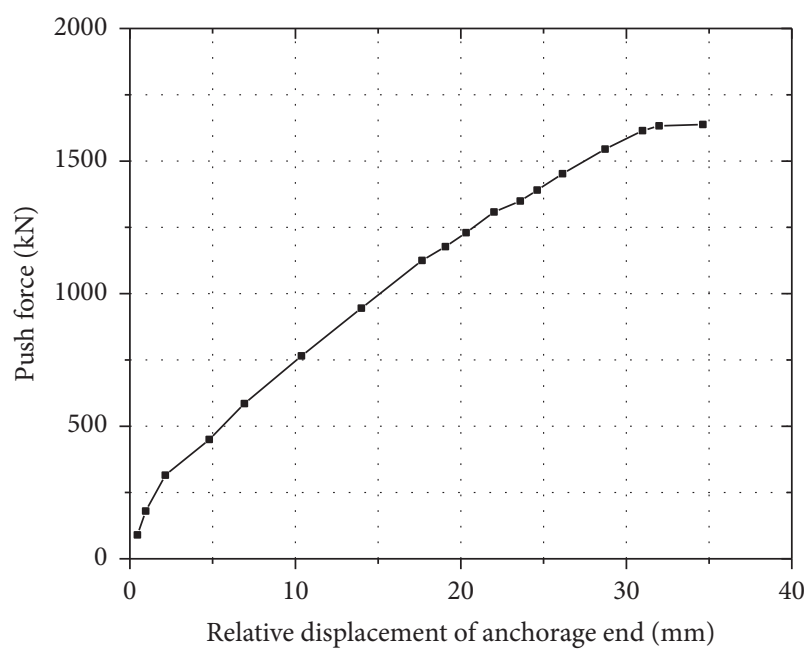

Figure 20: Load-displacement curve of the deck.

with the length of the broken cable. Compared with that of the load-displacement curve in Figure 20, the relative displacement of the deck subjected to a single cable breakage is within the cracked stage and will not lead to a deck collapse. Under the worst conditions, the deck system has a safety

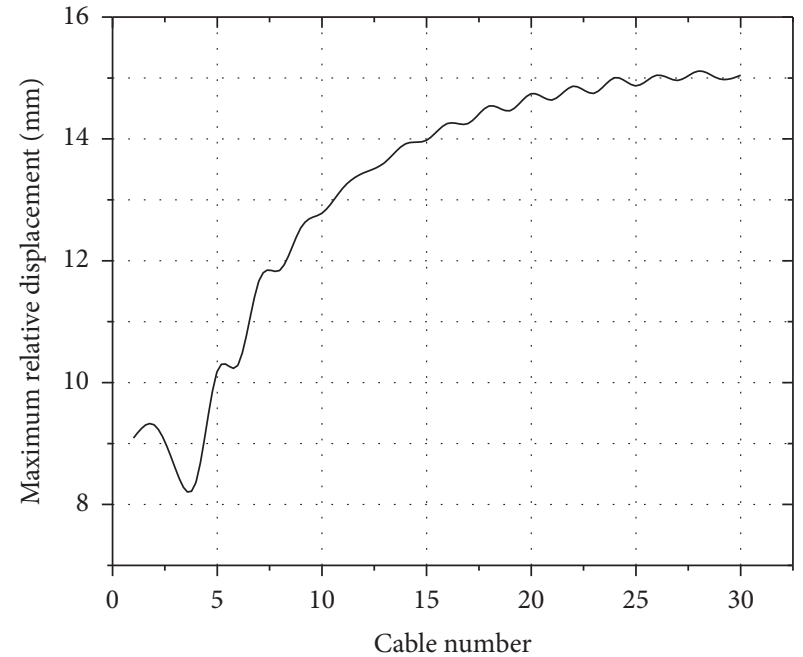

Figure 21: Maximum relative deck displacements caused by a single cable break.

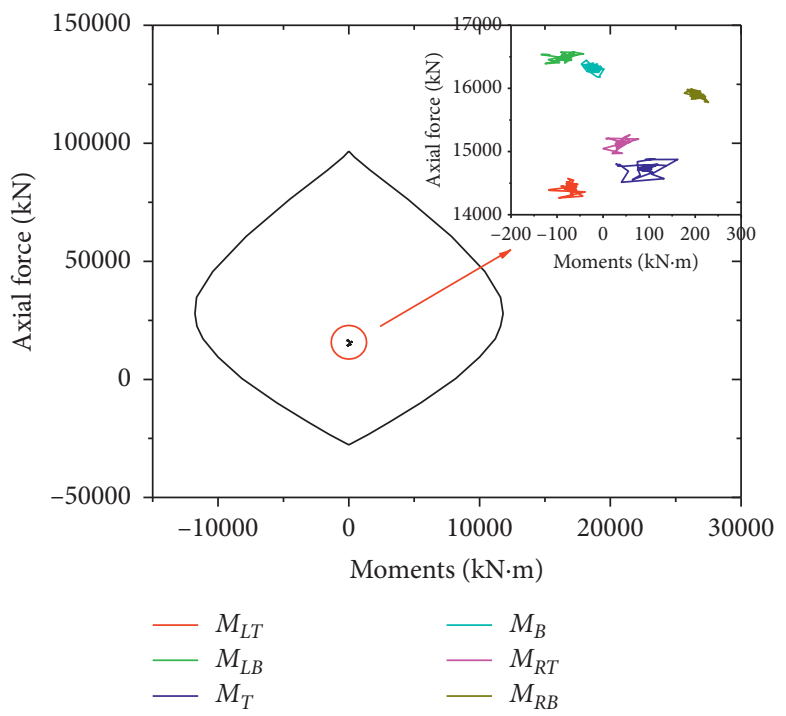

Figure 22: Internal force change curves of the arch rib due to cable S1 break within its M-N curves.

factor of approximately 2.0, which indicates that the deck system has relatively lower robustness than the cable system.

5.3. Robustness of the Arch Rib. To evaluate the robustness of the arch rib, which is an eccentric compression member, an M-N curve was drawn to evaluate its bearing capacity. Figures 22 and 23 show the axial force and bending moment curves of the arch rib subjected to S1 and S30 cable break, respectively. The curves in the circle are the internal force curves of the arch rib, which are enlarged at the upper right of the figure. It is observed that the arch ribs are mainly under compression. The axial force is between $14,000 \mathrm{kN}$ and $17,500 \mathrm{kN}$, and the bending moment is between -150 and $450 \mathrm{kN} \cdot \mathrm{m}$. The impact effect caused by the cable break 


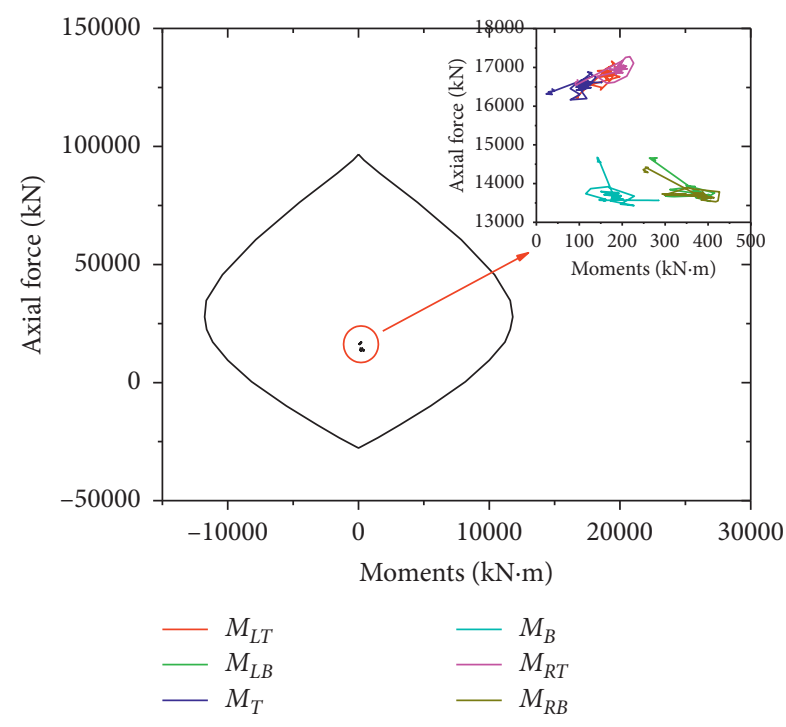

FIgURE 23: Internal force change curves of the arch rib due to cable S30 break within its M-N curves.

was within $20 \%$ of the arch rib bearing capability, indicating that the failure of a single cable does not cause failure of the arch rib. The safety factor of the arch rib is greater than 5.0, which reveals that the arch rib has sufficient robustness subjected to single cable breakage.

\section{Conclusions}

Cable breaking is common damage in cable-supported arch bridges as a result of aging and erosion caused by the harsh environment. To evaluate the dynamic response and robustness of cable-supported arch bridges subjected to cable breaking, a nonlinear dynamic simulation procedure and robustness evaluation method are developed in this study. A prototype arch bridge with a single cable break was analyzed as an example. Several critical factors for cable breakage simulation, such as the cable break mode, cable break duration, and damping, are studied. The dynamic responses of the cable system, deck, and rib are evaluated, and the DAF of different components of the cable-supported arch bridge is also discussed. Robustness evaluation indexes of the cable system, deck, and arch rib are calculated, and their robustness levels are evaluated. The main conclusions are as follows:

(1) Using an appropriate simulation method is essential to the dynamic analysis of a cable breaking process. Directly removing the failed cable in an appropriate time step of a transient analysis can effectively simulate the cable breaking effect. When the cable break duration is sufficiently short, the maximum impact effect can be fully attained regardless of the type of the break simulation mode used. The Rayleigh damping coefficient calculated by a higherorder frequency can avoid the suppression effect of a local vibration and better reflect the local vibration caused by a cable break.

(2) The closest cable to the broken cable receives the largest impact effect. The impact effect of the cable tension caused by the break of a short cable is greater than that of a long cable. The deck displacement and bending moment increase with the length of the failure cable. The breaking of a downstream cable has little effect on the upstream cables.

(3) The DAF of each component is different. The DAF of cable tension is between 1.4 and 1.6, while that of the deck displacement is between 1.3 and 1.65. The arch rib bending moment has the largest DAF that is between 1.5 and 2.4, which is greater than the PTI recommended value of 2.0 in some cases. Using a unified DAF of 2.0 cannot satisfy all the components of cable-supported arch bridges.

(4) The deck system is the least robust component of cable-supported arch bridges. The cable system has a safety factor of 3.1 under the cable breakage accidental combination; a single cable break will not trigger progressive damage. The arch rib has sufficient robustness subjected to a single cable breakage, though it has the largest DAF.

The results obtained by this analysis are conducive to the design and robustness evaluation of cable-supported arch bridges. Although only the breakage of a single cable was demonstrated, the proposed methodology can be applied to multiple cable breakage scenario of cable-supported bridges. Future research can be carried out in different types of cablesupported arch bridges subjected to multiple cable breakages.

\section{Data Availability}

The data that support the findings of this study are available from the corresponding author upon reasonable request.

\section{Conflicts of Interest}

The authors declare that there are no conflicts of interest regarding the publication of this paper.

\section{Acknowledgments}

The authors would like to acknowledge Professor Ruinian Jiang of NMSU for providing help during the preparation of the manuscript, and the authors also gratefully acknowledge the support of Taizhou Highway Administration. This research was funded by the Zhejiang Provincial Transportation and Transportation Office Technology Funding Project (2012H47).

\section{References}

[1] PTI, Recommendations for Stay Cable Design, Testing and Installation, Post-Tensioning Institute, Farmington Hills, MI, USA, 2012.

[2] T. Zoli and R. Woodward, "Design of long span bridges for cable loss," IABSE Symposium Report, vol. 90, no. 9, pp. 17-25, 2005.

[3] A. M. Ruiz-Teran and A. C. Aparicio, "Response of underdeck cable-stayed bridges to the accidental breakage of stay 
cables," Engineering Structures, vol. 31, no. 7, pp. 1425-1434, 2009.

[4] C. M. Mozos and A. C. Aparicio, "Parametric study on the dynamic response of cable stayed bridges to the sudden failure of a stay, Part I: bending moment acting on the deck," Engineering Structures, vol. 32, no. 10, pp. 3288-3300, 2010.

[5] C. M. Mozos and A. C. Aparicio, "Parametric study on the dynamic response of cable stayed bridges to the sudden failure of a stay, Part II: bending moment acting on the pylons and stress on the stays," Engineering Structures, vol. 32, no. 10, pp. 3301-3312, 2010.

[6] Y. Zhou and S. Chen, "Time-progressive dynamic assessment of abrupt cable-breakage events on cable-stayed bridges," Journal of Bridge Engineering, vol. 19, no. 2, pp. 159-171, 2014.

[7] Y. Park, U. Starossek, H.-M. Koh, J. F. Choo, H. Kim, and S. W. Lee, "Effect of cable loss in cable stayed bridges-focus on dynamic amplification," IABSE Symposium Report, vol. 93, no. 5, pp. 9-16, 2007.

[8] J.-g. Cai, Y.-x. Xu, L.-p. Zhuang, J. Feng, and J. Zhang, "Comparison of various procedures for progressive collapse analysis of cable-stayed bridges," Journal of Zhejiang University Science A, vol. 13, no. 5, pp. 323-334, 2012.

[9] Y. Xiang, Z. Chen, Y. Yang, H. Lin, and S. Zhu, "Dynamic response analysis for submerged floating tunnel with anchorcables subjected to sudden cable breakage," Marine Structures, vol. 59, pp. 179-191, 2018.

[10] Y. F. Zhou and S. R. Chen, "Framework of nonlinear dynamic simulation of long-span cable-stayed bridge and traffic system subjected to cable-loss incidents," Journal of Structural Engineering, vol. 142, no. 3, 2016.

[11] W. L. Qiu, M. Jiang, and C. L. Huang, "Parametric study on responses of a self-anchored suspension bridge to sudden breakage of a hanger," Scientific World Journal, vol. 2014, Article ID 512120, 10 pages, 2014.

[12] W. Qiu, M. Jiang, and Z. Zhang, "Responses of self-anchored suspension bridge to sudden breakage of hangers," Structural Engineering and Mechanics, vol. 50, no. 2, pp. 241-255, 2014.

[13] C. M. Mozos and A. C. Aparicio, "Numerical and experimental study on the interaction cable structure during the failure of a stay in a cable stayed bridge," Engineering Structures, vol. 33, no. 8, pp. 2330-2341, 2011.

[14] V. Hoang, O. Kiyomiya, and T. An, "Experimental and numerical study of lateral cable rupture in cable-stayed bridges: case study," Journal of Bridge Engineering, vol. 23, no. 6, 2018.

[15] M. Domaneschi, G. P. Cimellaro, and G. Scutiero, "Disproportionate collapse of a cable-stayed bridge," Proceedings of the Institution of Civil Engineers - Bridge Engineering, vol. 172, no. 1, pp. 13-26, 2019.

[16] M. Wolff and U. Starossek, "Cable loss and progressive collapse in cable-stayed bridges," Bridge Structures, vol. 5, no. 1, pp. 17-28, 2009.

[17] G. Wu, W. Qiu, and T. Wu, "Nonlinear dynamic analysis of the self-anchored suspension bridge subjected to sudden breakage of a hanger," Engineering Failure Analysis, vol. 97, pp. 701-717, 2019.

[18] M. Morgese, F. Ansari, M. Domaneschi, and G. P. Cimellaro, "Post-collapse analysis of morandi's polcevera viaduct in genoa Italy," Journal of Civil Structural Health Monitoring, vol. 10 , no. 1 , pp. $69-85,2020$.

[19] M. Shoghijavan and U. Starossek, "Structural robustness of long-span cable-supported bridges in a cable-loss scenario," Journal of Bridge Engineering, vol. 23, no. 2, 2018.

[20] M. Shoghijavan and U. Starossek, "An analytical study on the bending moment acting on the girder of a long-span cable- supported bridge suffering from cable failure," Engineering Structures, vol. 167, pp. 166-174, 2018.

[21] M. Domaneschi, C. Pellecchia, E. De Iuliis et al., "Collapse analysis of the Polcevera viaduct by the applied element method," Engineering Structures, vol. 214, p. 110659, 2020.

[22] O. Olamigoke, Structural Response of Cable-Stayed Bridges to Cable Loss, University of Surrey, Guildford, UK, 2018.

[23] J. Xu, H. H. Sun, and S. Y. Cai, "Effect of symmetrical broken wires damage on mechanical characteristics of stay cable," Journal of Sound and Vibration, vol. 461, 2019. 